\title{
Development Trend of Hotel Architectural Space in The Post- Epidemic Era
}

\author{
Zhang Yaoyao ${ }^{1}$ \\ ${ }^{1}$ Art \& Design Department, Gingko College of Hospitality Management, Chengdu, Sichuan, 611743, China
}

\begin{abstract}
At the beginning of 2020, the epidemic of COVID-19 broke out rapidly in countries all over the world. The sudden epidemic poses a significant impact on the operation of China's industrial economy. With the changes in the social and economic environment, hotels and tourism seem to have been pressed the "pause button" in a second, and instantly entered the "extremely cold" moment. The hotel occupancy rate plummeted to the "freezing point". In view of the large-scale outbreak of the epidemic in various countries, many architects and urbanists are rethinking the development direction of the hotel construction model in the post-epidemic era.
\end{abstract}

\section{Introduction}

At the beginning of 2020, the COVID-19 epidemic spread widely in a very short time, affecting people's lives. Under this new type of safety problem, the use of part of the architectural space has changed. At the present time of the normalization of the pandemic, this new type of security problem will affect the design and development of architectural space. After the outbreak of the epidemic, people's consumption habits have changed, multifunctional, personalized, intelligent, interesting, boutique has become the only way for hotel transformation and upgrading. In addition, the impact of Internet economy on hotel supporting, product pattern, hotel multi-dimensional space building, digital contactless service, environmental protection and health will be the direction of hotel development in the future.

\section{Architectural Space Design under the principle of Safety in the Post-epidemic era}

\subsection{Impact of epidemic on the use of architectural space}

COVID-19 is transmitted mainly through droplets and contact, which requires people to maintain a safe social distance, leading to changes in social distance.[1] The change in social distance affects the way buildings are used. In architectural design, designers often use Corbusier's "Le's modulus ruler" as a measurement, using human body components such as stride and limb length to measure the modular scale of buildings, so as to make buildings meet the needs of people's life and communication.[2] However, the epidemic of COVID-19 has changed this common scale, increasing the distance of close contact and increasing online communication at the same time. This change of "human modulus" is bound to bring changes to the use of buildings.

\subsection{Adaptive design}

Under the influence of COVID-19, the way of production and life has changed. Under this new type of safety problem, the importance of adaptive design of buildings has been highlighted. Elastic design can be reflected in two aspects: spatial function and facility layout: in terms of spatial function, buildings can carry out formal design and spatial division. With regard to the layout of facilities, different requirements can be met from the aspects of building equipment, building materials, building technology, etc. [3] In short, the adaptive design under the new safety problem is to redesign the building in the present and future of the normalization of the epidemic, so that the space can meet the new needs caused by the epidemic.

Table1. Analysis of Adaptive Design process under New Safety problems $[4]$

\begin{tabular}{|l|l|}
\hline \multicolumn{2}{|c|}{ Adaptive design process } \\
\hline $\begin{array}{l}\text { Space } \\
\text { selection }\end{array}$ & $\begin{array}{l}\text { Select a space with a space function to } \\
\text { change the foundation }\end{array}$ \\
\hline $\begin{array}{l}\text { Function } \\
\text { implantation }\end{array}$ & $\begin{array}{l}\text { Realize the change of space function } \\
\text { through the subdivision of space }\end{array}$ \\
\hline $\begin{array}{l}\text { Dynamic } \\
\text { update }\end{array}$ & $\begin{array}{l}\text { Re-divide the space according to the } \\
\text { different needs of users, and continue } \\
\text { to adjust according to changes in use } \\
\text { and environmental changes }\end{array}$ \\
\hline
\end{tabular}




\subsection{Selection of adaptive space}

Under the new security problems, not all spaces are suitable for elastic design, so how to choose a specific space for adaptive design is particularly important. The adaptive space under new security issues has the following characteristics:

(1) Sharing, which can be regarded as the degree of openness of the space under the new security problems. During the epidemic, the openness of part of the space changed, and the acceptance of the space to external users decreased, which will affect the users' use of space functions.

(2) Composition, which refers to the diversification of spatial functions. The compound of the hotel space can be reflected in whether the hotel faces the street or whether it is in the crowd gathering business district. The functional diversity of time can be reflected in whether the space has obvious time service attributes and whether it is only used in a specific time.

(3) Availability, which means that the transformation of spatial function can be carried out through the division of space, building equipment and building materials, for example, it is difficult to change the spatial function of some spaces with fixed facilities.

\section{Selection of Hotel Architectural space Materials in Post-epidemic era}

The inspiration of COVID-19 's epidemic situation to the future hotel space design is to pursue minimalist design in order to reduce the risk of indoor virus infection. In the face of infectious risks such as the coronavirus, designers should use healthy materials and indoor minimalist finished products in different design ways to make the hotel space safer and healthier.

According to the New England Journal of Medicine, Coronaviruses can survive for hours or even days on different surfaces. Scientists found that Coronaviruses survived in aerosol for a long time throughout the experiment, and survived longest on smooth surfaces. For example, Coronaviruses could survive 72 hours on the plastic surface of furniture, 72 hours on the surface of stainless steel appliances, and 24 hours on indoor paper, cardboard or clothes. The biggest surprise was the performance of copper: the virus disappeared on the surface of copper alloy utensils in only four hours.

Table2. Survival time of Coronaviruses on various materials

\begin{tabular}{|l|l|l|}
\hline Material & Items & $\begin{array}{l}\text { Duration } \\
\text { (unit: hour) }\end{array}$ \\
\hline Glass & $\begin{array}{l}\text { Windows, mirrors, mobile } \\
\text { phone screens, glass doors, etc. }\end{array}$ & 96 \\
\hline $\begin{array}{l}\text { Stainless } \\
\text { Steel }\end{array}$ & $\begin{array}{l}\text { Handrails, faucets, door } \\
\text { handles, coat hooks, paper } \\
\text { drawers, etc. }\end{array}$ & $48-72$ \\
\hline Plastic & $\begin{array}{l}\text { Take-out food containers, light } \\
\text { switches, mobile phone cases, } \\
\text { elevator buttons, etc. }\end{array}$ & $48-72$ \\
\hline Paper & $\begin{array}{l}\text { Newspapers, receipts, express } \\
\text { boxes, toilet paper, etc. }\end{array}$ & 24 \\
\hline Copper & $\begin{array}{l}\text { Door handles, handrails, copper } \\
\text { containers, etc. }\end{array}$ & 4 \\
\hline
\end{tabular}

\subsection{Door and window rail material}

When coronaviruses land on the hardest surface, they can survive for 2 to 5 days. But when they land on copper alloys such as copper and brass, they only last about four hours. Moreover, copper ion can be used as a disinfectant, anti-virus. This is one reason why old-fashioned doorknobs are made of brass. At the same time, hospitals also began to use a large number of copper products in the patient environment, so the use of copper products can be increased in hotel design.

\subsection{Flooring material}

Another inspiration from novel coronavirus to the hotel design is the use of ecologically healthy flooring materials. The first is to set the floor in the hotel room and refuse to lay the carpet, because the floor is easy to clean and easy to clean, avoiding dusty corners that are difficult to clean, and there is no hiding place for dust and insects. The main choices for ecologically healthy flooring materials are:

Vinyl flooring: this flooring material has always been a popular choice for environmentally friendly flooring. It has the advantages of warmth, dirt resistance and durability. It has solid flooring and its thin sheets and bricks.

Linoleum floor: made of natural materials such as cork oak, flaxseed oil, wood and resin. Because the floor is a pure green natural wood layer, it gives people a good feeling of living in nature, and when installed, maintained and used, it can enjoy the simplicity and convenience of reinforced composite wood flooring. It is a "real high-tech solid wood floor" that integrates the natural beauty of solid wood flooring and the firmness and durability of composite flooring.

Natural cork floor: the cork floor which is softened and dried by cork oak is completely natural and antibacterial. There are about 40 million air bags per cubic centimeter of cork, each of which is a small silent absorber, a small temperature insulator and a small flexible shock absorber. In the chemical composition of cork structure, cork does not contain sugar, starch and protein. Without protein, cork will not rot; without sugar and starch, there will be no food for bugs in cork, so using cork as hotel room floor material is naturally antibacterial and insect-proof.[5]

\subsection{Concrete and tile materials}

The requirements of COVID-19 epidemic on the hotel environment should not only be comfortable and clean, but also beneficial to the residential health care of antibacterial and detoxification, so the application of concrete and ceramic tile materials should also be committed to protecting the hotel building environment.

Photocatalytic concrete: the photocatalytic cement is prepared by adding human $\mathrm{TiO} 2$ into cement, which can produce photocatalytic reaction in ordinary sunlight. Photocatalytic concrete belongs to gas environmental material and health environmental material. It can catalyze sulfur dioxide and nitrogen oxides produced during 
combustion or emitted by motor vehicles, which are harmful to human health.

The gas is decomposed and removed, which plays a role in purifying the air; at the same time, it also has antibacterial functions such as sterilization and decontamination. This kind of cement not only has the characteristics of light weight, high temperature resistance and good flame retardancy, but also can produce high concentration of germicidal ions through the photocatalytic reaction of its own stored sunlight, so it has high antibacterial and antitoxic effect. it is a new material for hotel buildings in the post-epidemic era.

Antibacterial ceramic tile: it is on the basis of ordinary ceramic tile, through antibacterial technology, ceramic tile is endowed with antibacterial performance. Antibacterial ceramic tiles, not easy to breed bacteria, used in public places such as hotels, is very necessary to prevent bacterial infectious diseases.

\section{Design Strategy of Hotel Architectural space in the Post-epidemic era}

For the future development of the hotel after the COVID19 epidemic, the society, investors, designers and consumers should think accordingly, especially for the current practitioners in the design industry, the responsibility is particularly important. Designers should re-examine the design ideas of architectural space and pay more attention to the layout of space, especially private space, so as to adapt to the design and consumption needs under the epidemic.

\subsection{The principle of "people-oriented"}

It is mainly reflected in the design and treatment of privacy space. Hotel architecture and courtyard landscape do not seek luxury but internal quality and cultural connotation, fully reflect the ritual sense of life, and increase a little more independent space. This is the "people-oriented" design consideration under the epidemic, at the same time, it can also improve the experience of guests and the quality of the hotel.

\subsection{The mutual unity of function and form}

The relationship between function and form is a pair of contradictions that integrate and depend on each other. In the hotel architectural design, we should comprehensively consider the relationship between the internal function and form, use various techniques to make the two combine with each other, and emphasize the formal beauty on the basis of satisfying the hotel function, so as to design the hotel building with complete functions, rich forms and beautiful appearance.[6]

\subsection{The internal combination of technology and art}

The development of modern science and technology has not only changed the conditions for the use of architecture, but also changed people's concept of architecture. Due to the application of new technology, modern architecture promotes people to carry out technological innovation and material iteration constantly. In modern architectural design, including hotel architectural design, the application and expression of technology has been regarded as an innovative expression of art, which is the internal combination of technology and art.

\subsection{From contagion without boundaries to defense units}

Virus transmission has no boundaries, and urbanization enhances the ability of virus transmission. In the treatment of hotel architectural space, it is suggested that reasonable consideration should be given to the integration and blocking of urban space, and to establish an effective space system to prevent and deal with emergencies through "defense unit". In the past, the disorderly spread of urban development has caused some problems, such as too high complexity, difficult to disassemble as a whole, too difficult to regulate space and so on. Therefore, it is suggested to design the hotel architectural space based on the defense unit, which will increase the feasibility of the hotel to deal with emergencies and the security of the city as a whole.

\section{Conclusion}

In recent years, hotel architectural design is getting rid of the single mode of traditional standardized star hotels in a stable and gradual manner. Specifically, more and more design tasks are focused on these guest experiencecentered personalized boutique hotels, theme hotels, and luxury hotels. The design of hotel architecture is progressively divorced from the mainstream orientation of our architecture. From spatial sequence to artistic atmosphere, the interest pursued by hotel design is obviously different from that pursued by mainstream architecture: Hotel, as a leisure resort for people to enjoy the experience, has different emphasis and direction in the pursuit of space experience, which is different from the architecture which has inherited the ritual and commemorative architectural aesthetic genes since its birth.

In the long run, the COVID-19 pandemic will lead to changes in business models and consumption habits. [7]Accordingly, the construction of smart hotel, as a hotel with digital, intelligent and networked management through advanced information and communication technology, provides a goal and platform for the transformation and upgrading of the hotel industry.[8] Based on the smart hotel platform, the hotel industry may be able to build hotel formats with different themes and features, such as health-care hotels. It is generally believed that after this pandemic, consumers will inevitably favor it more. On the basis of the smart hotel platform, it is easy for convalescent hotels to realize the functions of remote booking, contactless facial scanning, room air disinfection, voice control room, guest sleep monitoring, toilet body fluid monitoring, online consultation, health care needs 
and so on through scientific and technological equipment with artificial intelligence as the core, which enables the hotel products no longer single, but more in line with the needs of consumers. Relying on the smart hotel technology platform, it is easy to achieve multi-format cross-border. If hotel products are linked to other industries, the hotel product line will be greatly enriched.

In the present and future of the normalization of the epidemic, how to make better use of different types of architectural space will become an issue of concern. Under the new security problems, designers should consider using Internet technology to release space under the premise of ensuring security, improve the flexibility of architectural space, make architectural space more antiepidemic resources, and meet people's new use needs.

\section{References}

1. Wang Jiao'e, Du Delin, Wei Ye, Et Al. Research on The Spatial Diffusion Process and Model of the COVID-19 Epidemic [J]. Geographical Research, 2020, 39(07): 1450-1462.

2. Lu Yue. Application Of Le Corbusier's Modular System in Architecture [J]. Shanxi Architecture, 2015, 41(07): $18+39$.

3. Zhou Qingwei. The Characteristic Expression of Flexible Design Concept in Architectural Design [J]. Ju She, 2019(23): 86.

4. Zhu Xiaofang, Chen Yawei, Dong Bei. Exploring The Layout of Community-Level Public Sports Facilities Under the Concept of Flexible Planning: Taking Zhenjiang Old Town as An Example [J]. Jiangsu Urban Planning, 2019(02): 16-22.

5. Wang Zhicheng, Werner Woolf, Jenny Woulfe.New Trends of residential building construction after epidemic situation[J]. Housing and real estate. 2020,(14)

6. Zhuang Zhaojian, Mei Qing.Rethinking the Design of Homestays in the Context of COVID-19:Taking Guangxi Practice as an Example[J]. Architecture and culture.2021(02)

7. Zheng Jianghuai, Fu Fu, Tao Jin. Impact of COVID19 Epidemic on consumption economy and Countermeasures $[\mathrm{J}]$. Consumption economy, 2020( 03) : 1-10.

8. State Administration for Market Regulation, China National Standardization Administration. GB/T 37976-2019. General technical requirements for the interface of the Internet of Things smart hotel application platform [S]. Beijing: China Standard Press, 2019 (08) 